\title{
Study of materials and techniques in painted ceiling panels from a palace in Cremona (Italy, $15^{\text {th }}$ century)
}

\author{
Marco Malagodi ${ }^{1,2}$, Tommaso Rovetta ${ }^{2^{*}}$ and Maurizio Licchelli ${ }^{1}$
}

\begin{abstract}
Background: This study concerns the analysis of four painted wooden panels from the second half of the $15^{\text {th }}$ century which embellish the ceiling of a palace situated in Cremona (Northern Italy). This type of painting was generally used to decorate the top of the walls and the ceilings of the rooms in aristocratic palaces and they usually portray the owner's ancestors, family members or important visitors. The paintings are of historical importance since they enable us to study the clothing and hair styles which were in fashionable in Italy during the Renaissance. These panels were heavily damaged and required a lot of restoration including the cleaning of the paint layers. This enabled us to carry out a thorough examination of the materials and techniques used for creating these paintings.

Results: Various micro-samples were taken in order to distinguish the materials and, in particular: (i) to analyze the ground layer and study its function; (ii) to typify the organic binders and the pigments of the polychrome films. The stratigraphic sequence of micro-samples was analyzed using optical microscopy, the elemental composition was determined by means of the SEM-EDX technique while the organic binders were analyzed by means of $\mu \mathrm{FT}-\mathrm{IR}$ spectroscopy. The main component of ground layer proved to be clay. The organic binder was probably composed of a protein-based material such as animal glue. This type of ground layer is similar to the traditional $15^{\text {th }}$ century Flemish formula and seems to confirm the strong influence of that artistic technique in Northern Italy. Cross-section investigation showed a primer layer over the ground layer made of white lead pigment. In fact, a white primer was used to cover the ground layer of yellowish clay common in Central Europe. The importance of this research is also confirmed by the study of paint films, for which pigments such as azurite or cinnabar were used. Red lake pigment for painting the subjects' complexions was emphasized.
\end{abstract}

Conclusions: The analyses provide new detailed information concerning the materials used for painting the ceiling panels, the layer sequence of the paints and Northern Italian $15^{\text {th }}$ century painting techniques.

Keywords: Paint layer, Ceiling panels, Renaissance artworks, Clay, Pigments, $\mu F T-I R$, SEM-EDX

\section{Introduction}

Aesthetic sensibility for interior furniture was of great importance from the $15^{\text {th }}$ century onwards and structural elements such as walls and ceilings were also decorated in order to embellish the interior of buildings. Wooden ceilings represented an important and widespread art form in Italy [1]. Skilled craftsmen operating in several notable "ateliers", mainly located in northern Italy, decorated ceiling panels with subjects inspired by

\footnotetext{
*Correspondence: tommaso.rovetta@unipv.it

${ }^{2}$ Laboratorio Arvedi di analisi diagnostiche non invasive, Università degli Studi di Pavia, Museo del Violino, via Bell'Aspa 3, 26100 Cremona, Italy Full list of author information is available at the end of the article
}

the artworks of famous painters, for instance Andrea Mantegna, Vincenzo Foppa or Giovan Pietro da Cemmo. Painted wooden panels were mainly produced to enhance the ceilings of aristocratic homes and churches [2]. Today these panels represent an important source of information about $15^{\text {th }}$ and $16^{\text {th }}$ century customs and traditions as the subjects of the decorations were typical of the Renaissance [3]. At that time, the wooden ceilings had a typical structure with central beams and lateral rafters with the presence of a console along the vertical faces. The surfaces of the beams were painted and decorated and small wooden panels were hung between the beams and the console [4]. These artworks were given a

\section{() Chemistry Central}

(c) 2014 Malagodi et al.; licensee Chemistry Central Ltd. This is an Open Access article distributed under the terms of the Creative Commons Attribution License (http://creativecommons.org/licenses/by/2.0), which permits unrestricted use, distribution, and reproduction in any medium, provided the original work is properly credited. The Creative Commons Public Domain Dedication waiver (http://creativecommons.org/publicdomain/zero/1.0/) applies to the data made available in this article, unless otherwise stated. 
ground layer which provided the base for painting. Although a lot of these paintings have been lost over the centuries, some of them can still be found in Italian museums or in the original buildings, as for example the painted ceiling panels depicting knights which adorn the ground floor of a building in Vittorio Veneto (Treviso) dating back to 1476, or the palace of Giovanni degli Onesti in Udine [5]. This artistic technique was commonly used in Lombardy and examples of these panels can be seen all over the region. The panels are usually square shaped and depict various subjects such as bust-length portraits of noblewomen or gentlemen, historical, mythological or allegoric episodes, as well as portraits of kings or emperors. Mantova, Brescia, Cremona and Pavia were the most important towns in Lombardy for the development of these decorations [6]. From a technical point of view, Spruce was the main source of wood for the panels due to its ease of workability and soft color. At that time, light-colored wood was commonly treated with pigments, organic dyes, gums, natural resins or oil varnishes in order to give a transparent rosy color to the wood surfaces, conferring to wood a pleasant effect [7]. Moreover, some of the most commonly used pigments for these kinds of paintings were azurite for bleu colors and cinnabar for red, as confirmed by historical sources [8]. The ceiling panels analyzed in this study are part of a group of panels that probably come from a stately home in Cremona which no longer exists and belong to the "Musei Civici" in Cremona. The paintings are portraits of fashionable dames, with rich jewels and fancy headdresses, who were probably the aristocratic owners of the palace. The panels seem to be quite well preserved and no restoration has been documented in the past. Nothing is known about the binders, primer layers and pigments and it is unclear if paintings were made by the same or different workshops and/or artists of the town. A scientific evaluation performed by means of various diagnostic methods is required in order to assess the level of degradation of the painted panels and their materials. Moreover, the analyses of the paintings' components may provide useful information about the painting techniques [9]. The analyses performed on micro-samples taken from characteristic points of different pattern colors enabled us to study the stratigraphy of the ground layer and paint layers. The samples were studied with an optical microscope, $\mu$ FT-IR microspectroscopy and Scanning Electron Microscopy with EDX spectrometer (SEM-EDX). The characterization of these materials represents a first step in determining the artistic techniques used to make these particular kinds of artworks during the Italian Renaissance period.

\section{Materials and methods}

Four micro-samples were taken from different points of the four panels (Figure 1). The samplings were carried out by using a biopsy needle in order to gather micro-samples measuring less than one millimeter in diameter. Sample T2 came from a panel with the portrait of a woman and was taken from the complexion color of her face; T3 sample was taken from the red color of a woman's headdress of a second panel; sample T4 comes from the edge of a third panel where the primer layer was visible. The last T5 sample comes from the green background of a fourth panel that depicts another woman's portrait. A summary of the characteristics of the samples and the analyses performed is reported in Table 1.

Fourier Transform Infrared ( $\mu$ FT-IR) micro-spectroscopy analyses were performed with a Nicolet iN10 Thermo Fischer $\mu$ FT-IR spectroscope, in Attenuated Total Reflectance (ATR) mode with germanium crystal and in reflection-absorption mode on gold foil following the treatment of some micro-fragments with $\mathrm{H}_{2} \mathrm{O}$ used as solvent to solubilize the binding media from the pigments. The spectral range was $4000-700 \mathrm{~cm}^{-1}$ with a resolution of $4 \mathrm{~cm}^{-1}$. A small amount of various micro-samples was embedded in epoxy resin and cut using a diamond blade. The cross-sections were first abraded with carbon papers (800-500 mesh) and then polished using diamond pastes $(6,3,1,0.25 \mu \mathrm{m})$. The cross sections were observed under
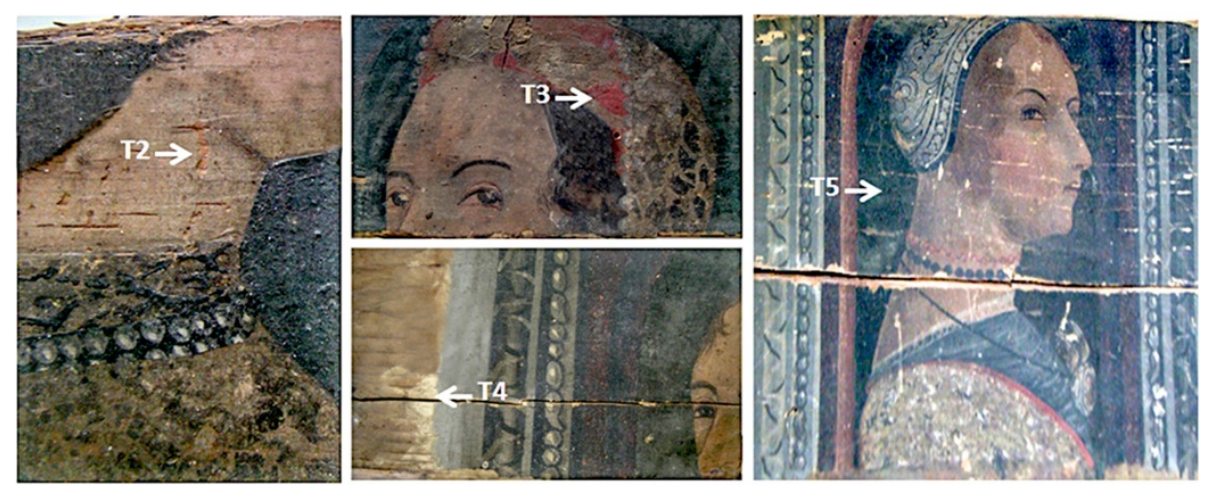

Figure 1 Sampling points on the celing panels. T2, complexion color; T3, red color; T4, ground layer; T5, green dark color. 
Table 1 Sampling summary

\begin{tabular}{|c|c|c|c|}
\hline Sample & Area of sampling & Sample description & Analyses \\
\hline T2 & Complexion color of the neck & $\begin{array}{l}\text { Absence of a ground layer; presence of a thin } \\
\text { colored layer on wood }\end{array}$ & $\mu F T-I R$ SEM-EDX \\
\hline T3 & Red color of a woman headdress & Evidence of a thick red paint and ground layer & HFT-IR SEM-EDX Optical Microscopy \\
\hline T4 & $\begin{array}{l}\text { Ground layer visible on the edge } \\
\text { of the portrait }\end{array}$ & Homogeneous and thick material; yellowish color & $\mu F T-I R$ \\
\hline T5 & $\begin{array}{l}\text { Green background behind the } \\
\text { neck of the woman portrait }\end{array}$ & $\begin{array}{l}\text { Evidence of a dark-green paint layer with not homogeneous } \\
\text { surface; presence of a small blue area on the edge of the } \\
\text { paint layer }\end{array}$ & HFT-IR SEM-EDX Optical Microscopy \\
\hline
\end{tabular}

a Leitz Laborlux polarizing microscope (VIS and UV lamps) and then sputtered with an Au coating, using a Cressington 208HR sputter. Scanning Electron Microscopy (SEM) images and energy-dispersive X-ray spectra (EDX) were collected by using a Tescan FE-SEM instrument (MIRA XMU series) equipped with EDAX spectrometer. The microanalyses were performed maintaining the current electron beam at $20 \mathrm{kV}$, with counts of $100 \mathrm{~s}$ per analysis. The semi-quantitative data were obtained by processing the measurements with the EDAX Genesis software.

\section{Results and discussion}

In general the study of the cross sections shows several superimposed paint layers illustrating a complex painting technique. The paintings often contained an intermediate layer between the ground and the paint layers called "imprimitura" (priming layer) which was made of oils and/or resins or proteinaceous binders and fillers. Their function is to ensure adhesion between the paint layers, to protect the underlying paint layer, and, in the case of the imprimitura, to fix the underdrawn and reduce the absorbency of the ground layer [10].

\section{Ground layer}

At first the analysis focused on the comparative study of the ground layers of three different panels (samples T3, T4 and T5), in order to analyze their chemical composition. The microscopic examination of samples T3 and T5 that were mounted as cross-sections reveal the presence of at least two layers under the paint film: a thick yellowish ground (Figure 2A, 1), and a thin white layer (Figure 2A, 2). The ground layer of both samples does not appear to be homogeneous and is made of mineral grains which are mainly micrometric in size (less than $2 \mu \mathrm{m}$ of diameter) and show different colors and shapes. Under UV light the cross-section of the T3 sample shows only one layer under the paint film (Figure 2B, 2), with a diffused brown fluorescence. It is a well known fact that many organic materials become fluorescent after being excited by ultraviolet radiation and, in particular, organic binders can be detected by fluorescence imaging techniques [11]. Therefore the brown emission observed in sample T3 could be due to the presence of a proteinaceous material used as binder in the ground layer (Figure 2B, 1).

The EDX analyses performed on different areas of the ground layer show emission peaks of $\mathrm{K}, \mathrm{Si}, \mathrm{Al}, \mathrm{O}$ that could be due to the presence of K-feldspar minerals (Figure 3A). The relative amounts of $\mathrm{Al}, \mathrm{Si}, \mathrm{Mg}, \mathrm{K}, \mathrm{Ca}$, and the high emission of Fe, probably related to an iron hydroxide and/or oxide pigment such as hematite, suggests the presence of a natural clay as main component [12]. The low intensity of the $\mathrm{S}$ peak, if compared to the $\mathrm{Ca}$, suggests that calcium sulphates (gypsum, $\mathrm{CaSO}_{4} \cdot 2 \mathrm{H}_{2} \mathrm{O}$ )

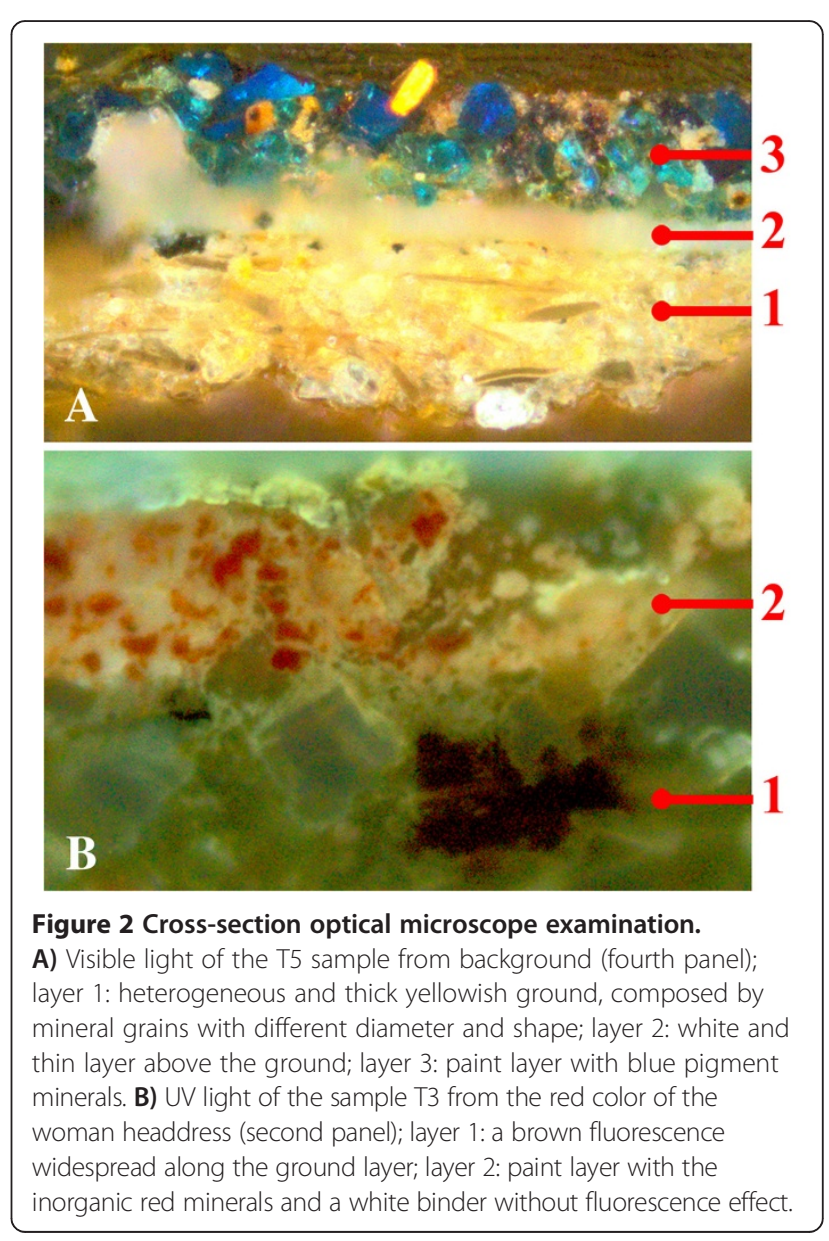



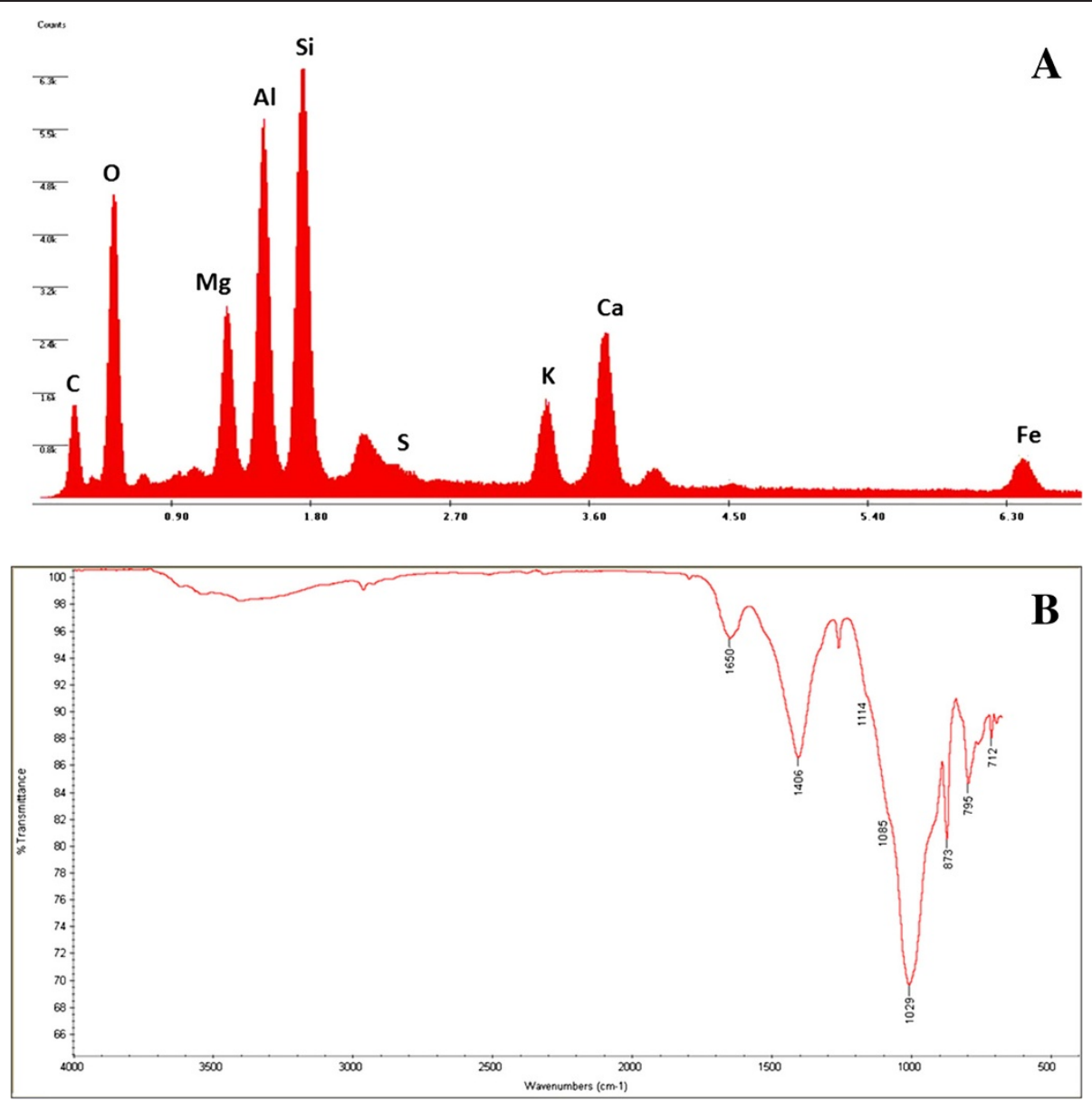

Figure 3 Analytical characterization of ground layer. A) EDX spectrum of T5 ground layers; B) $\mu$ FT-IR spectrum of T4 ground layer sample.

are only present in small amounts. It should be noted that traces of gypsum are naturally present in clays.

Further information about the composition of the panels ground layer, come from the $\mu \mathrm{FT}$-IR analysis performed on the T4 sample: the main absorption bands are due to silicates $\left(1029 \mathrm{~cm}^{-1}\right)$, sulphates $\left(1114 \mathrm{~cm}^{-1}\right.$, with a weak shoulder at $\left.1085 \mathrm{~cm}^{-1}\right)$, and carbonates $\left(1406 \mathrm{~cm}^{-1}\right)$. Moreover, the peak at $1650 \mathrm{~cm}^{-1}$ can be due to the $\mathrm{N}-\mathrm{H}$ stretching absorption which is a characteristic of proteinaceous binders such as animal glue (Figure 3B), possibly used as organic binder of this layer and in accordance with the fluorescent image observed in the UV cross section examination.

These compositional results are very important because in Italy it was not a common practice to use clay as the main material of the ground layer. One of the most famous manuals concerning painting techniques and materials is the early renaissance work by Cennino Cennini, first published in 1437, in which all the main formulas were described. Ground layers applied to wood panel surfaces were already very common at that time and they were usually made of gypsum mixed with proteinaceous glue binder (mestica). This ancient recipe was particularly widespread in Italy, because of the bright white color and the low level of shrinkage of the ground layer. The use of a clay-based ground layer in these panels could be due to the influence of Northern European artistic techniques [13] and it is strictly related to the great increase in trading between northern Europe and Lombardy. Following Gothic times, Flemish artworks reached the most outlying regions and Flemish artists travelled to almost every southern European country, either as students or as workmen, as they were sometimes more skilled than the natives [14]. Clay minerals, at times mixed with chalk grounds, were present in the grey layer that was observed in $14^{\text {th }}$ century Central-European wooden panel paintings and sculptures [13]. The similar composition of the ground layer and relative amounts of the elements observed in the three samples could suggest a univocal origin of the panels.

\section{Primer layer}

A primer layer was detected on the clay ground layer in samples T3 and T5. SEM images (back-scattered electron, BSE) of the T3 sample show bright white color particles 
inside indicating the presence of chemical elements with a very high atomic weight. The corresponding EDX analyses performed on the single grains indicate the presence of $\mathrm{Pb}$ as the major element of this layer (Figure 4A), with a lower concentration of Carbon and Oxygen. The same compositional data were obtained from the analyses carried out on the primer layer of sample T5 (Figure 4B), even if it appears to be less homogeneous and continuous in this case. The relative amounts of these elements suggest the presence of white pigments such as white lead [15]. White lead $\left.\left[\left(\mathrm{PbCO}_{3}\right)_{2} \cdot \mathrm{Pb}(\mathrm{OH})_{2}\right)\right]$ is the most important of all lead pigments and historically it was the most widely used of all white colors from ancient times to the present day [16]. The use of a lead white primer, sometimes in combination with other white pigments as such as gypsum, was a quite common practice in Northern Europe [16]. The purpose of the white primer was to cover the ground layer with a more homogeneous coating and confer a shiny white color as base for the paint layer at the same time. This was a common practice over a clay ground layer in order to cover the natural yellowish hue of this material and it seems to confirm the influence of the Flemish culture in Northern Italian artistic techniques. Furthermore, the presence of this white lead primer layer in both samples represents further proof of this artistic technique.

\section{Paint layer}

Firstly, a paint layer analysis was carried out on the red headdress of the second panel in sample T3. Optical microscopic observations indicate that the layer is composed of two superimposed paint layers: the lower orange and the upper red. In order to distinguish the various materials of this stratigraphic sequence, several SEM-EDX experiments were performed. The EDX analyses carried out on the orange layer, showed characteristic emission peaks of $\mathrm{Si}, \mathrm{Al}, \mathrm{K}, \mathrm{S}$ with high level of $\mathrm{Fe}$; this elemental composition could be correlated to the widespread presence of K-feldspar and Iron hydroxide and/or oxide, as for example red hematite [17]. The emission peak of $\mathrm{Pb}$ was also observed which could be due to the presence of red lead $\left(\mathrm{Pb}_{3} \mathrm{O}_{4}\right)$ (Figure 5). Red hematite was commonly identified as the main red pigment in paintings of the same historical period. It was often associated with small amounts of other red minerals, e.g. cinnabar or minium which did not greatly modify its hue. The addition of red lead to red ochre was a common practice, already mentioned by Pliny [18]. In fact, red-orange and red-purple colors were generally obtained by using different pigments (e.g. cinnabar, red madder, red lead, red ochres earths) sometimes in mixtures. The ochres were also used as colored preparation layers for deeper red paint layers made by cinnabar or minium [19]. EDX analyses of the lower paint layer also show the presence of As and $S$ which could be due to realgar crystals, mineral pigment added by the artist in order to give this layer an orange hue [20]. High emission peaks of $\mathrm{Hg}$ and $\mathrm{S}$ elements observed by EDX analyses performed on the red upper layer (Figure 5) could be attributed to the pigment cinnabar ( $\mathrm{HgS})$. Cinnabar was an expensive but widely used pigment which was frequently mixed with cheaper pigments, usually with red lead [21]. In general, the color of cinnabar ranges from scarlet through brownish red to black and even grey and this variation is mainly caused by the type and amount of impurities. In the past, the adulteration of this expensive

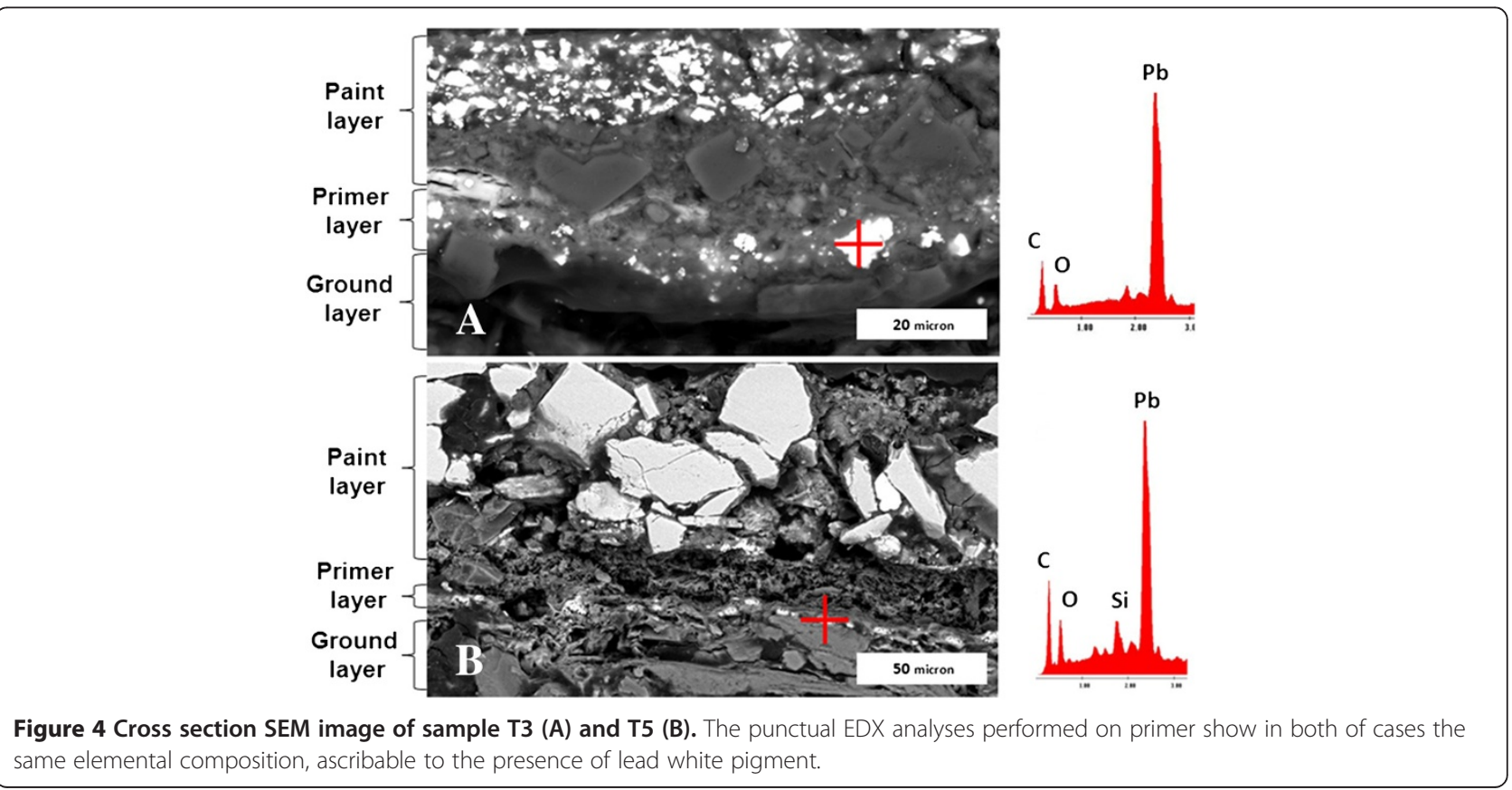




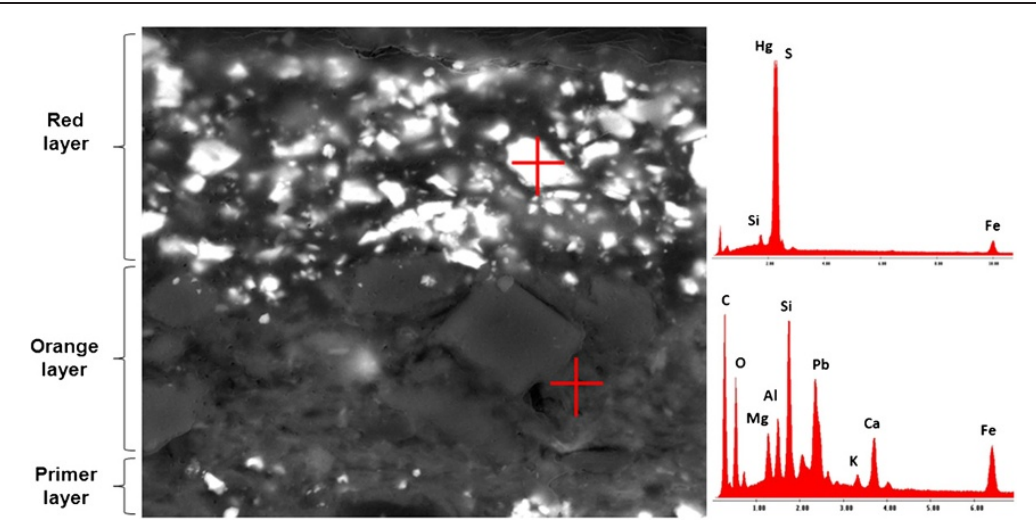

Figure 5 SEM-EDX analyses on the cross section paint layer of T3 sample.

pigment with lead tetra oxide or arsenic sulfides, both realgar and orpiment, was a common practice, mainly for its cost rather than artistic reasons [22]. Historically cinnabar was widely used to paint robes and mantles of the various characters and to represent objects and decorative elements in artworks in general. Moreover, cinnabar was used in mixtures with other pigments such as lead white in order to obtain the complexion tones [23].

The cross section study, performed by optical microscopy, of the T5 sample from the green background of the fourth panel, enabled us to identify a mixture of green and blue color grains in the paint layer (Figure 2A). The SEM investigation confirmed the presence of a homogeneous layer made of crystals of various sizes, ranging from 5 to $30 \mu \mathrm{m}$. EDX analyses performed on the grains showed characteristic peaks of $\mathrm{Cu}$ and $\mathrm{C}$ (Figure 6A). This result suggests the presence of copper carbonate but it does not exclude other pigments such as e.g. copper oxalates. The $\mu F T-I R$ measurements, concurrently with other diagnostic techniques, could provide further information about the paint layer pigments [24] and it may be used to distinguish azurite and malachite minerals by studying the stretching vibration according to their hydroxide group: azurite spectrum only shows one peak at $3426 \mathrm{~cm}^{-1}$, while in malachite spectrum two bands at 3400 and $3320 \mathrm{~cm}^{-1}$ are observed [25]. The $\mu$-FTIR spectrum obtained from T5 sample (Figure 6B) shows a good match with the azurite standard spectrum, as the characteristic absorption peaks of this pigment are observed: $3428 \mathrm{~cm}^{-1}$ (only one peak), 951 and $835 \mathrm{~cm}^{-1}$ (weak peaks) $1408 \mathrm{~cm}^{-1}$ (strong peak)

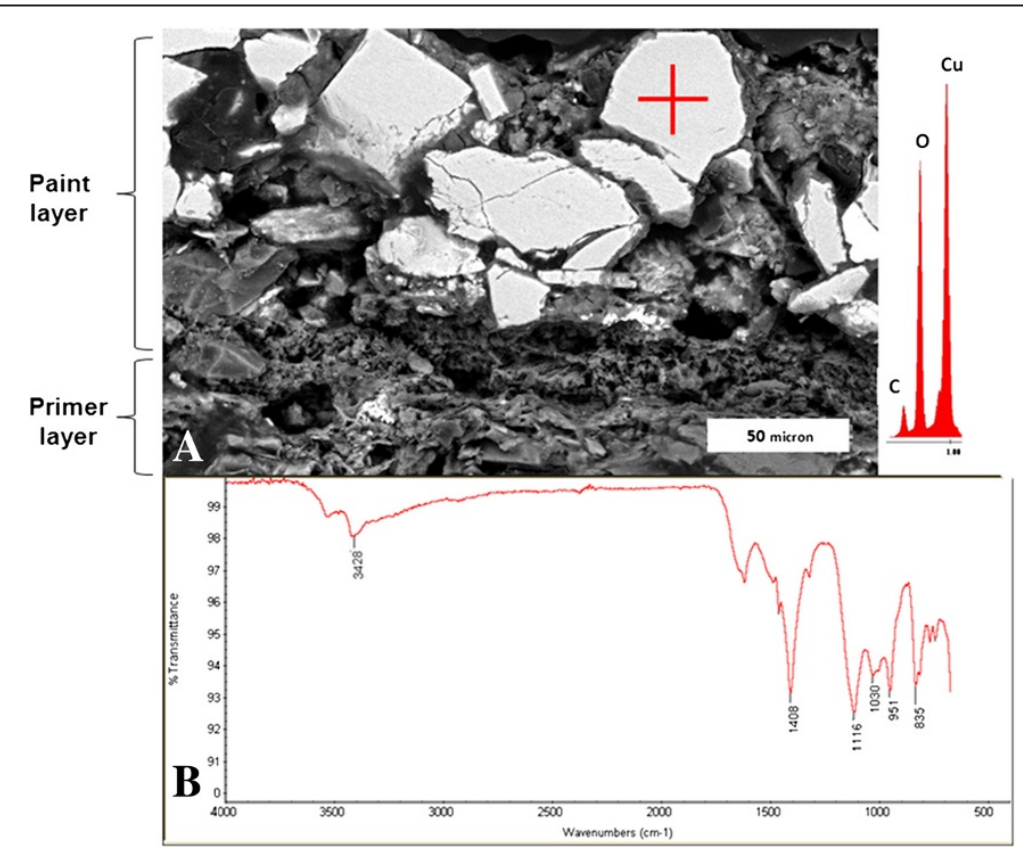

Figure 6 Cross section of T5 sample from green background (fourth panel). A) SEM-EDX analysis performed on paint mineral pigment, with the corresponding elemental composition spectrum; B) $\mu \mathrm{FT}$-IR spectrum performed on paint layer. 


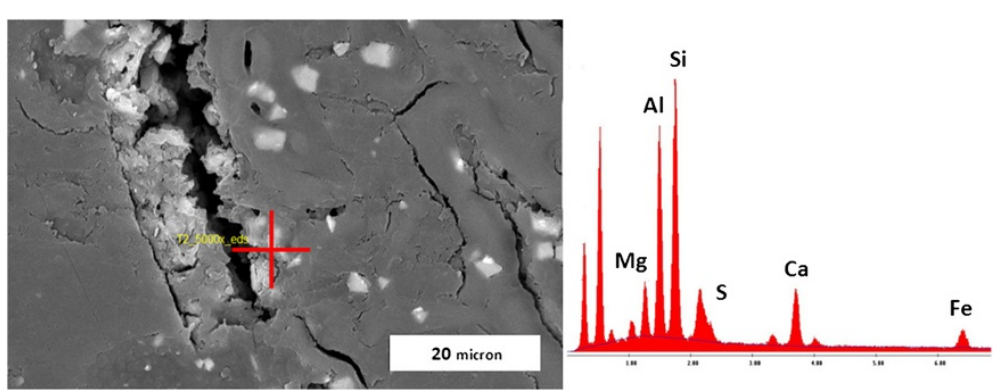

Figure 7 SEM EDX analysis performed on the grains of the T2 sample from complexion paint.

and at $1030 \mathrm{~cm}^{-1}$. Moreover, the IR spectrum showed typical vibration bands of sulphates, centered at $1109 \mathrm{~cm}^{-1}$, as well as the stretching and deformation vibrations of the $\mathrm{O}-\mathrm{H}$ bond of water at $3525 \mathrm{~cm}^{-1}$ and at 1692 and $1627 \mathrm{~cm}^{-1}$, respectively, which could be attributed to gypsum. Weak bands due to calcium oxalate $\left(\mathrm{CaC}_{2} \mathrm{O}_{4} \cdot \mathrm{nH}_{2} \mathrm{O}\right)$ were also observed at 1324 and $780 \mathrm{~cm}^{-1}$. Other bands expected for calcium oxalate at $1640-1620 \mathrm{~cm}^{-1}$ could not be clearly assessed due to the gypsum absorptions in the same wavenumber range.

These results, together with information given by optical microscopy and SEM investigations, seem to confirm the presence of azurite mineral as the main pigment for the paint, although the presence of traces of copper oxalate cannot be ruled out. The green color in the background of the fourth panel could be due to a partial alteration of the azurite pigment [26]. The blue background made of azurite has often been seen to turn into green malachite, e.g. in the blue robe of the Virgin
Mary in many oil paintings which have frequently become greenish. As a compositional material, azurite $\left[\mathrm{Cu}\left(\mathrm{CO}_{3}\right) \cdot 2 \mathrm{Cu}(\mathrm{OH})_{2}\right]$ has a relatively rare carbonate of copper base, which is formed chiefly by the action of carbonated waters on other copper minerals in the upper oxidized zone of the deposits [27]. Similarly to azurite, malachite $\left[\mathrm{Cu}\left(\mathrm{CO}_{3}\right) \cdot \mathrm{Cu}(\mathrm{OH})_{2}\right]$ has a carbonate of copper base and a secondary mineral found in copper deposits, although it is more common than azurite. The main interest in these minerals stems from their use in art works. In fact, azurite may have been employed as a paint pigment as early as the Fourth Dynasty in Egypt and was the most important blue pigment in European painting from the Middle Ages [26,27].

The last T2 sample was taken with the aim of distinguishing the materials used for the complexion tones. Unlike the previous samples, the cross section examination, by means of optical and electron microscopy, shows the absence of distinct stratigraphic layers. However, the SEM

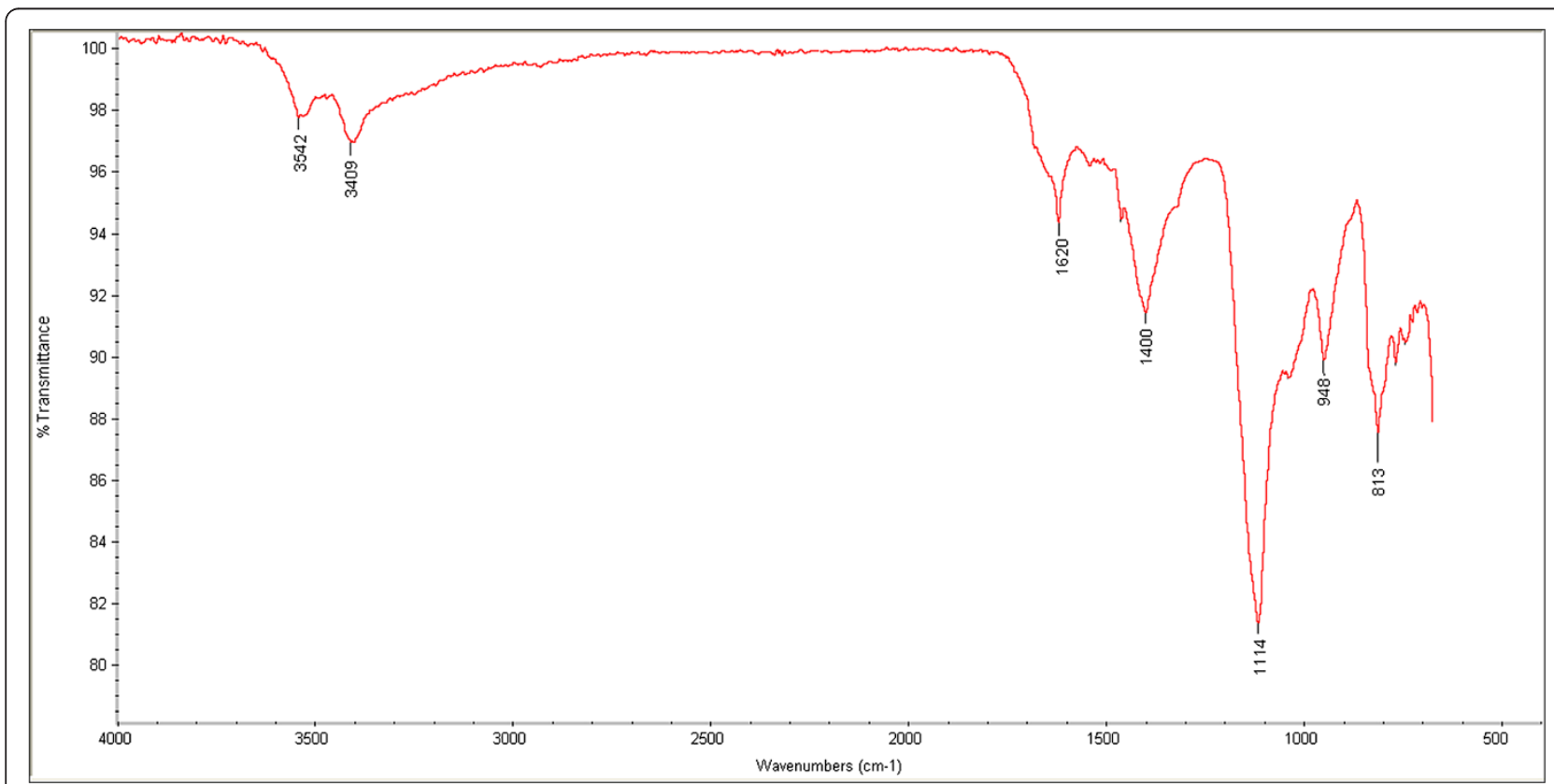

Figure $8 \mu \mathrm{FT}$-IR spectrum of T2 sample performed on the soluble fraction after extraction with water. 
analysis at higher magnification of the sample indicates the presence of widespread inorganic grains over the wood surface (Figure 7). The EDX analysis performed on the single grains indicated the presence of $\mathrm{Si}$ and $\mathrm{Al}$, associated with $\mathrm{Mg}, \mathrm{Ca}, \mathrm{K}$ and $\mathrm{Fe}$. A weak emission of $\mathrm{S}$ was also detected. The relative concentrations of the elements seem to be related to the presence of aluminum silicate crystals, with traces of calcium sulphates. The presence of these minerals is not directly related to the color of the complexion due to the white color of the grains. This result, together with the evidence of the pink color of the complexion, suggests the use of an organic chromogenic material. Historically, the most important natural red colorants, extensively used long before the $15^{\text {th }}$ century for the complexions of portraits on wood paintings, were red lakes, red colorants often bonded on to a metal salt. The main coloring matters found in these lake pigments are all substituted derivatives of naphtoquinones and anthroquinones [28]. Most red lakes were obtained by extraction of the dyestuff by alkali, with the subsequent addition of alum to precipitate the pigment, yielding a substrate containing $\mathrm{Al}$ and $\mathrm{O}$ (i.e. amorphous hydrated alumina). The exact nature of the inorganic substrate produced depends on a number of factors including the order of addition of the alum and the alkali during lake preparation. When a substrate was made in this way, examination by $\mu$ FT-IR could only reveal the presence of $\mathrm{Al}-\mathrm{O}$ bands. In fact, although the natural dyestuff components could be readily distinguished in the pure state by means of IR spectroscopy, its content is very low in traditional red lake pigments and the IR spectra tend to be dominated by bands deriving from the inorganic substrate. For this reason, the $\mu$ FT-IR analysis of the inorganic materials could represent an alternative method of lake identification [29].

In order to extract and characterize the lake salts present on the surface of the T2 sample, the micro-sample was treated with water and the soluble fractions were analyzed with a $\mu$ FT-IR in reflection mode (Figure 8 ). The spectrum showed absorption bands at around 3409 and $1620 \mathrm{~cm}^{-1}$ due to coordinated water, the band associated to vibrations of the $\mathrm{Al}-\mathrm{O}$ crystal lattice at $948 \mathrm{~cm}^{-1}$, and the peaks expected for sulphates and carbonates at $1114 \mathrm{~cm}^{-1}$ and $1400 \mathrm{~cm}^{-1}$, respectively. This confirmed the presence of inorganic components of the lake pigment, while it did not provide any information about the organic colorant. It should be noted that it is an extremely difficult task to identify such organic colorants due to their very high tinting power and consequently their very small concentration on the painting surfaces [30].

\section{Conclusions}

The results of this research provide new information concerning the artistic techniques used on ceiling panels during the Renaissance in Italy. The analyses were performed on micro-samples in order to characterize the pigments of the colored painted films, the composition of the ground layers and to make some hypotheses concerning the nature of the organic binders. The analysis of the stratigraphic sections enabled us to recognize clay minerals mixed with gypsum as ground layer, possibly held together by a proteinaceous material, e.g. animal glue which is an unusual mixture for Italian artistic traditions. This choice is probably due to the strong influence of the Flemish culture in Northern Italy, also for the paint ceiling panels of stately homes, blending artistic techniques and materials. Moreover, $\mu$ FT-IR and SEM-EDX techniques have enabled us to determine the same ground layer composition of three panels. Results suggest that the artworks share a common origin, i.e. they come from the same palace in Cremona, or that the panels were made by the same artistic workshop. The presence of a thin primer layer made of white lead covering the ground layer confirms the Flemish influence and indicates a high technological standard of making. The study of the layers of the paintings has emphasized the use of high quality and expensive pigments such as cinnabar and azurite, proving the importance of this kind of artwork at that time. Moreover, the presence of a red lake applied directly onto the wood for the complexion tone of a woman's portrait appears to be very interesting: the artistic aim of this technique was probably related to the transparent effect of the varnish obtained on the panel surface.

\section{Abbreviations}

SEM-EDX: Scanning electron microscopy-energy dispersive x-ray microanalysis; HFT-IR: Micro fourier transform-infrared spectroscopy; ATR: Attenuated total reflectance.

\section{Competing interests}

The authors declare that they have no competing interests.

\section{Authors' contributions}

All authors contributed to data analyses and to finalizing the manuscript. All authors have read and approved the final version.

\section{Acknowledgements}

We would like to thank Dr. Elisabetta Arrighetti and Dr. Roberto Bonomi from the Restoration School of Botticino, Italy, for their cooperation during sampling and results discussion and Dr. Mario Marubbi, Conservator of Musei Civici "Ala Ponzone", Cremona, Italy, for his valuable advice.

\section{Author details}

'Dipartimento di Chimica, Università degli Studi di Pavia, via Taramelli 12, 27100 Pavia, Italy. ${ }^{2}$ Laboratorio Arvedi di analisi diagnostiche non invasive, Università degli Studi di Pavia, Museo del Violino, via Bell'Aspa 3, 26100 Cremona, Italy.

Received: 23 October 2013 Accepted: 7 March 2014 Published: 17 March 2014

\section{References}

1. Malaguzzi Valeri F: Pittori lombardi del Quattrocento. Milano: L. F. Cogliati; 1902.

2. Bonfadini P: Colori di legno. Soffitti con tavolette dipinte a Brescia e nel territorio (secoli XV-XVI). Brescia: Starrylink Editrice; 2006.

3. Baxandall M: Painting and Experience in Fifteenth Century Italy. Oxford: Oxford University Press; 1972. 
4. Terni De Gregory W: Pittura artigiana lombarda del Rinascimento. Milano: Cassa di Risparmio delle Provincie Lombarde; 1958.

5. Fiaccadori G, Grattoni D'Arcano M: In domo habitationis, l'arredo in Friuli nel tardo medioevo. Venezia: Marsilio; 1996.

6. Romanini AM: Un nuovo complesso di tavolette da soffitto quattrocentesche ritrovate a Pavia. Milano: Edizioni arte lombarda; 1959.

7. Santini C: Mille mobili veneti, L'arredamento domestico in Veneto dal sec. XV al sec. XIX. Modena: Artioli; 1999.

8. Segre-Montel C: La pittura dell'Italia settentrionale nell'età gotica. Milano: Fabbri; 1966.

9. Popescu CM, Dobele G, Rossinskaja G, Dizhbite T, Vasile C: Degradation of lime wood painting supports: evaluation of changes in the structure of aged lime wood by different physico-chemical methods. J Anal Appl Pyrolysis 2007, 79:71-77.

10. Franquelo ML, Duran A, Herrera LK, de Haro MC J, Perez-Rodriguez JL: Comparison between micro-Raman and micro-FTIR spectroscopy techniques for the characterization of pigments from Southern Spain Cultural Heritage. J Mol Struct 2009, 924-926:404-412.

11. Comelli D, D'andrea C, Valentini G, Cubeddu R, Colombo C, Toniolo L: Fluorescence lifetime imaging and spectroscopy as tools for nondestructive analysis of works of art. Appl Opt 2004, 43:2175-2183.

12. Lau D, Villis C, Furmanc S, Livett M: Multispectral and hyperspectral image analysis of elemental and micro-Raman maps of cross-sections from a $16^{\text {th }}$ century painting. Anal Chim Acta 2008, 610:15-24.

13. David H, Grygar T's, Hradilova J, Bezdicka P: Clay and iron oxide pigments in the history of painting. Appl Clay Sci 2003, 22:223-236.

14. Friedley D: Study Rooms in the Department of Decorative Arts. New York: The Metropolitan Museum of Art Bulletin; 1915.

15. Castillejoa M, Martin M, Silva D, Stratoudaki T, Anglos D, Burgio L, Clark JH: Laser-induced breakdown spectroscopy and Raman microscopy for analysis of pigments in polychromes. J Cult Herit 2000, 1:297-302.

16. Rutherford JG, Kühn H, Chase WT: Lead White. Stud Conserv 1967, 12:125-139.

17. Eastaugh N, Walsh V, Chaplin T, Siddall R: Pigment Compendium, A Dictionary and Optical Microscopy of Historical Pigments. Oxford: Elsevier; 2008.

18. Bearat $\mathrm{H}$ : Chemical and mineralogical analyses of gallo-roman wall painting from Dietikon. Archaeometry 1996, 38:81-95.

19. Hein A, Karatasios I, Mourelatos D: Byzantine wall paintings from Mani (Greece): microanalytical investigation of pigments and plasters. Anal Bioanal Chem 2009, 395:2061-2071.

20. Harley RD: Artists' Pigments C. 1600-1835: A Study in English Documentary Sources. 2nd edition. London: Butterworth Scientific; 1982

21. Palet A: Tratado de pintura: color, pigmento y ensayo. Barcelona: Ed. Universitat de Barcelona; 2002.

22. Frost RL, Edwards HGM, Duong L, Kloprogge JT, Martens WN: Raman spectroscopic and SEM study of cinnabar from Herod's palace and its likely origin. Analyst 2002, 127:293-296.

23. Boselli L, Bracci S, Magrini D, Picollo M: The Polittico di Ognissanti by Giovanni da Milano: Painting Technique and Colorimetric Evaluation of Cleaning Tests. In The CREATE 2010 Conference. Edited by Simone G, Hardeberg JY, Farup I. Norway: Gjøvik; 2010:53-56.

24. Huang CK, Kerr PF: Infrared study of the carbonate minerals. Am Mineral 1960, 45:311-324.

25. Frost RL, Martens WN, Rintoul L, Mahmutagic E, Kloprogge JT: Raman spectroscopic study of azurite and malachite at 298 and 77 K. J Raman Spectrosc 2002, 33:252-259.

26. Kerber $G$, Koller M, Mairinger F: Studies of blue-green alterations into Austrian Mediaeval wall paintings. In reports of ICOM Committee for Conservation 3rd Triennial Meeting. Madrid: ICOM Committee for Conservation; 1972. 6/72/1, (AATA 14-95).

27. Rutherford JG, West Fitzhugh E: Azurite and Blue Verditer. Stud Conserv 1966, 11:54-61.

28. Maguregui Ml, Alonso RM, Barandiaran M, Jimenez RM, Garcia N: Micellar electrokinetic chromatography method for the determination of several natural red dyestuff and lake pigments used in art work. J Chromatogr 2007, 1154:429-436.
29. Kirby J, Spring M, Higgitt C: The technology of Red Lake pigment manufacture: study of the dyestuff substrate. National Gallery Tech Bull 2005, 26:71-87.

30. Leona M, Stenger J, Ferloni E: Application of surface-enhanced Raman scattering techniques to the ultrasensitive identification of natural dyes in works of art. J Raman Spectrosc 2006, 37:981-992.

doi:10.1186/2050-7445-2-9

Cite this article as: Malagodi et al:: Study of materials and techniques in painted ceiling panels from a palace in Cremona (Italy, $15^{\text {th }}$ century). Heritage Science 2014 2:9

\section{Publish with ChemistryCentral and every scientist can read your work free of charge \\ "Open access provides opportunities to our colleagues in other parts of the globe, by allowing anyone to view the content free of charge." W. Jeffery Hurst, The Hershey Company. \\ - available free of charge to the entire scientific community \\ - peer reviewed and published immediately upon acceptance \\ - cited in PubMed and archived on PubMed Central \\ - yours - you keep the copyright \\ Submit your manuscript here: \\ http://www.chemistrycentral.com/manuscript/<smiles>c1ccccc1</smiles> \\ Chemistry Central}

